\title{
Use of a Multispectral Radiometer for Noninvasive Assessments of Foliar Disease Caused by Ray Blight in Pyrethrum
}

Sarah J. Pethybridge and Frank Hay, Tasmanian Institute of Agricultural Research (TIAR), University of Tasmania, Burnie, Tasmania, 7320, Australia; Paul Esker, Department of Plant Pathology, Iowa State University, Ames 50011; Calum Wilson, TIAR, University of Tasmania, New Town Research Laboratories, New Town, Tasmania, 7008, Australia; and Forrest W. Nutter, Jr., Department of Plant Pathology, Iowa State University, Ames 50011

\begin{abstract}
Pethybridge, S. J., Hay, F., Esker, P., Wilson, C., and Nutter, F. W., Jr. 2007. Use of a multispectral radiometer for noninvasive assessments of foliar disease caused by ray blight in pyrethrum. Plant Dis. 91:1397-1406.

Foliar disease due to ray blight (Phoma ligulicola) in pyrethrum was quantified at three locations over 2 years in Tasmania, Australia. To obtain a range of ray blight disease intensities, replicated plots were treated with fungicides that varied in efficacy to control ray blight. Visual disease assessments and measurement of canopy reflectance were made at least once during spring (September through December). Visual assessments involved removal of flowering stems at ground level from which measurements of defoliation severity and the incidence of stems with ray blight were obtained. Reflectance of sunlight from pyrethrum canopies was measured at 485, 560, 660, 830 , and 1,650 nm using a handheld multispectral radiometer. Measurements from these wavelengths also were used to calculate all possible reflectance ratios, as well as four vegetative indices. Relationships between wavelength bands, reflectance ratios, vegetative indices, and disease intensity measures were described by linear regression analyses. Several wavelength bands, ratios, and vegetative indices were significantly related in a linear fashion to visual measures of disease intensity. The most consistent relationships, with high $R^{2}$ and low coefficients of variation values, varied with crop growth stage over time. The ratio $830 / 560$ was identified as the best predictor of stem height, defoliation severity, and number of flowers produced on each stem in October. However, reflectance within the near-infrared range $(830 \mathrm{~nm})$ and the difference vegetative index was superior in November. The use of radiometric assessment of disease was noninvasive and provided savings in disease assessment time, which is critical where visual assessment is difficult and requires destructive sampling, as with pyrethrum.
\end{abstract}

Additional keywords: CropScan, remote sensing

The most significant foliar disease of pyrethrum (Tanacetum cinerariaefolium L.) in Tasmania, Australia is caused by Phoma ligulicola Baker, Dimock \& Davis v. Arx (41). Severe annual epidemics of this disease can cause entire field loss in early spring (August and September) in the absence of appropriate disease management practices. P. ligulicola also causes the disease ray blight in the closely related genus, chrysanthemum. Severe losses have been documented in chrysanthemum $(2,3,12)$, where disease management strategies include fungicides $(3,4,46)$, minimization of overhead irrigation and liquid fertilizers (12), resistant cultivars (1), and the use of certified disease-free cuttings or planting material (4). The disease is manifested as a variety of symptoms on all aboveground parts of the pyre-

Corresponding author: S. J. Pethybridge

E-mail: sarah_jp@utas.edu.au

Accepted for publication 17 May 2007.

doi:10.1094/PDIS-91-11-1397

(C) 2007 The American Phytopathological Society proach to disease assessment provides an accurate, precise, and reproducible methodology (32), the dense pyrethrum canopy that is present from October onward makes sampling difficult. Moreover, sampling is invasive, time consuming, and destructive to the productivity of the crop. Remote sensing may provide an alternative method of disease assessment, which can be implemented to reduce subjectivity in the selection of stem sampling units from the field $(25,29)$, as well as providing a noninvasive and nondestructive method to obtain assessments $(25,31)$.

Remote sensing can be defined as the acquisition of measurements from a sampling unit such as a plant canopy without physical contact between the measuring device and the sampling unit $(25,29,31)$. Multispectral radiometers that are held above the crop canopy are common remote-sensing instruments that have been used to quantify foliar disease intensity and yield losses in a range of pathosystems $(7,20,21,33,35,43)$. These studies have detected significant quantitative relationships between percentage of reflectance measurements and foliar disease intensity. For example, Nutter (28) reported that reflectance at $800 \mathrm{~nm}$ could be used to estimate the intensity of peanut late leaf spot in the field. Significant correlations also have been reported throughout the near-infrared reflectance range (700 to $1,300 \mathrm{~nm}$ ) for smut and barley stripe disease $(26,27)$, and for Rhizoctonia blight in creeping bentgrass (42).

Because sampling in pyrethrum crops becomes increasingly difficult as harvest approaches, we hypothesize that a multispectral radiometer could provide quantitative and precise information regarding ray blight disease without sacrificing accuracy, precision, and reproducibility. Accuracy is defined as the difference between an observation and the true value of that parameter. Precision is the variation among a group of observations and can be estimated by comparing coefficient of variation values $(32,44)$. Reproducibility is defined as the variation between two sets of observations taken at different times (44), which can include assessments performed at different times (10). Therefore, the objectives of this study were to determine the relationship between disease intensity and percent canopy reflectance, and to identify 
the individual wavelength bands, reflectance ratios, and vegetative indices that best quantify the relationship between reflectance-based assessments with visual disease intensity assessment methods.

\section{MATERIALS AND METHODS}

Field sites. Trials were conducted in three different pyrethrum fields over 3 years in northern Tasmania, Australia. These locations included Sisters Creek $\left(40^{\circ} 95^{\prime} \mathrm{S} ; 1^{\circ} 45^{\circ} 58^{\prime} \mathrm{E}\right)$ in 2002 , and Table Cape $\left(40^{\circ} 57^{\prime} \mathrm{S} ; 145^{\circ} 39^{\prime} \mathrm{E}\right)$ and Wynyard $\left(40^{\circ} 58^{\prime} \mathrm{S} ; 145^{\circ} 42^{\prime} \mathrm{E}\right)$ in 2004 . In year one, all fields were approaching their first harvest and each field received similar standard production practices, including irrigation, fertilizer, fungicide, and herbicide applications. The same cultivar, 'A' (proprietary), was used for the trials at Sisters Creek and Table Cape whereas, at Wynyard, a different proprietary cultivar, 'B,' was grown.

Manipulation of foliar disease intensity. In each trial, a range of disease intensities of foliar disease was generated through the application of fungicides that varied in efficacy (40). The experimental design for trials in all fields utilized a completely random design with five replications. The efficacy of fungicides on reducing disease intensity at Sisters Creek has been reported (40). In the Sisters Creek trial, six fungicides were used: azoxystrobin (150 g a.i./ha), didecyldimethylammonium chloride (36 g a.i./ha), chlorothalonil (1,008 g a.i./ha), polysulfide sulfur $(1,800 \mathrm{~g}$ a.i./ha), mancozeb $(1.8 \mathrm{~kg}$ a.i./ha), copper oxychloride (750 g a.i./ha), and a nontreated control. Fungicides were applied on 11 September, 22 September, and 9 October at volumes of 300 liters of water (equivalent) per hectare using a custom-built (propane/butane) sprayer (Crop Care Australasia Pty. Ltd., York, Western Australia). The sprayer was fitted with a 2$\mathrm{m}$ boom with flat fan nozzles spaced 50 $\mathrm{cm}$ apart and was pressurized by propane/butane at $200 \mathrm{kPa}$. Each plot was $7 \mathrm{~m}$ long and $5 \mathrm{~m}$ wide, with $1-\mathrm{m}$ buffers of nontreated pyrethrum surrounding each plot.

At Table Cape and Wynyard, foliar disease intensity was manipulated using difenoconazole (125 g a.i./ha), chlorothalonil (1,008 g a.i./ha), azoxystrobin (150 g a.i/ha), kresoxim-methyl (150g a.i./ha), a premixture of pyraclostrobin $(150 \mathrm{~g}$ a.i./ha) and boscalid (504 g a.i./ha), epoxiconazole (125 g a.i./ha), a premixture of chlorothalonil (750 g a.i./ha) and pyrimethanil (300 g a.i/ha), and a nontreated control. At Table Cape, fungicides were applied on 24 August, 12 September, and 3 October. At Wynyard, fungicides were applied on 27 August and 6 October. At both sites, applications were made using a petrol-driven Solo 432 sprayer with volumes of 300 liters of water (equivalent) per hectare at $200 \mathrm{kPa}$, using a
Table 1. AOV ranks for regression statistics ${ }^{a}$ averaged across trials for defoliation severity, stem height, the number of flowers produced on each stem, and incidence of stems with ray blight in October and November

\begin{tabular}{|c|c|c|c|c|}
\hline \multirow[b]{2}{*}{ Measurement, period ${ }^{\mathrm{c}}$} & \multirow[b]{2}{*}{$\mathbf{W}, \mathbf{R}, \mathbf{V I}^{\mathbf{d}}$} & \multirow[b]{2}{*}{$R^{2}$} & \multicolumn{2}{|c|}{ AOV rank ${ }^{b}$} \\
\hline & & & SEEy & $\mathbf{C V}$ \\
\hline \multicolumn{5}{|l|}{ Defoliation severity } \\
\hline \multirow[t]{7}{*}{ October } & $830 \mathrm{~nm}$ & 5.67 & 7.00 & 7.33 \\
\hline & $830 / 560$ & 1.00 & 1.00 & 2.30 \\
\hline & $830 / 660$ & 1.67 & 2.30 & 2.00 \\
\hline & $1,650 / 830$ & 3.00 & 4.00 & 3.67 \\
\hline & DVI & 4.67 & 5.33 & 5.00 \\
\hline & RDVI & 4.00 & 5.33 & 6.00 \\
\hline & NDVI & 2.67 & 4.00 & 3.33 \\
\hline \multirow[t]{7}{*}{ November } & $830 \mathrm{~nm}$ & 2.67 & 3.33 & 2.67 \\
\hline & $830 / 560$ & 4.00 & 4.00 & 3.50 \\
\hline & $830 / 660$ & 3.50 & 3.50 & 3.00 \\
\hline & $1,650 / 830$ & 4.00 & 4.67 & 5.67 \\
\hline & DVI & 2.67 & 2.67 & 5.00 \\
\hline & RDVI & 3.67 & 4.00 & 6.33 \\
\hline & NDVI & 7.00 & 7.00 & 6.50 \\
\hline \multicolumn{5}{|l|}{ Stem height } \\
\hline \multirow[t]{10}{*}{ October } & $830 \mathrm{~nm}$ & 2.50 & 4.00 & 3.50 \\
\hline & $830 / 560$ & 1.00 & 1.00 & 1.00 \\
\hline & $830 / 660$ & 3.00 & 3.50 & 3.00 \\
\hline & $660 / 560$ & 6.00 & 7.50 & 7.00 \\
\hline & $1,650 / 560$ & 7.00 & 4.50 & 8.00 \\
\hline & $1,650 / 830$ & 4.50 & 6.00 & 5.50 \\
\hline & DVI & 2.50 & 2.50 & 2.50 \\
\hline & RDVI & 3.00 & 3.00 & 3.00 \\
\hline & NDVI & 4.00 & 4.50 & 4.00 \\
\hline & GNDVI & 6.50 & 8.00 & 7.50 \\
\hline \multirow[t]{10}{*}{ November } & $830 \mathrm{~nm}$ & 2.33 & 3.00 & -0.11 \\
\hline & $830 / 560$ & 3.50 & 5.50 & 0.00 \\
\hline & $830 / 660$ & 4.00 & 5.00 & -0.13 \\
\hline & $660 / 560$ & 6.00 & 10.50 & -1.31 \\
\hline & $1,650 / 560$ & 7.00 & 9.50 & -1.07 \\
\hline & $1,650 / 830$ & 3.67 & 4.67 & -0.25 \\
\hline & DVI & 2.33 & 2.30 & -0.08 \\
\hline & RDVI & 3.00 & 4.00 & -0.09 \\
\hline & NDVI & 5.50 & 7.50 & -0.21 \\
\hline & GNDVI & 5.50 & 6.50 & -1.24 \\
\hline \multicolumn{5}{|l|}{ Number of flowers/stem } \\
\hline \multirow[t]{7}{*}{ October } & $830 \mathrm{~nm}$ & 4.00 & 4.00 & 4.00 \\
\hline & $830 / 560$ & 1.00 & 1.00 & 1.00 \\
\hline & $830 / 660$ & 3.00 & 2.50 & 3.00 \\
\hline & $1,650 / 830$ & 3.00 & 2.50 & 3.00 \\
\hline & DVI & 3.00 & 3.00 & 3.00 \\
\hline & RDVI & 3.50 & 3.50 & 3.50 \\
\hline & NDVI & 4.50 & 3.50 & 4.50 \\
\hline \multirow[t]{7}{*}{ November } & $830 \mathrm{~nm}$ & 2.00 & 2.00 & 2.00 \\
\hline & $830 / 560$ & 7.00 & 7.00 & 7.00 \\
\hline & $830 / 660$ & 5.00 & 5.00 & 5.00 \\
\hline & $1,650 / 830$ & 4.00 & 4.00 & 4.00 \\
\hline & DVI & 1.00 & 1.00 & 1.00 \\
\hline & RDVI & 3.00 & 3.00 & 3.00 \\
\hline & NDVI & 7.00 & 7.00 & 7.00 \\
\hline \multicolumn{5}{|c|}{ Incidence of stems with ray blight } \\
\hline \multirow[t]{9}{*}{ October } & $830 \mathrm{~nm}$ & 5.00 & 8.00 & 8.00 \\
\hline & $830 / 560$ & 2.50 & 3.00 & 4.50 \\
\hline & $830 / 660$ & 2.00 & 2.00 & 2.00 \\
\hline & $1,650 / 830$ & 1.50 & 2.00 & 2.00 \\
\hline & DVI & 4.00 & 6.50 & 6.50 \\
\hline & RDVI & 3.50 & 6.00 & 5.50 \\
\hline & NDVI & 2.50 & 3.00 & 3.00 \\
\hline & GNDVI & NA & NA & NA \\
\hline & & & (conti & next page) \\
\hline
\end{tabular}

a Statistics: coefficients of determination $\left(R^{2}\right)$, coefficients of variation $(\mathrm{CV})$, and standard error of the estimate of y (SEEy)

${ }^{b}$ Ranking relative to the highest (best) regression model statistic. $\mathrm{NA}=$ not applicable.

c Plant and disease measurements and period of radiometric assessment.

${ }^{\mathrm{d}}$ Wavelengths $(\mathrm{W})$, ratios $(\mathrm{R})$, and vegetative indices (VI) results shown only when $R^{2}$ is greater than 0.3 and $F$ statistics $=0.0001$ at all locations. NDVI $=$ normalized difference vegetative index, GNDVI = green normalized difference vegetative index, DVI $=$ difference vegetative index, and RDVI $=$ renormalized difference vegetative index 
Table 1. (continued from preceding page)

\begin{tabular}{|c|c|c|c|c|}
\hline \multirow[b]{2}{*}{ Measurement, period ${ }^{\mathrm{c}}$} & \multirow[b]{2}{*}{$\mathbf{W}, \mathbf{R}, \mathbf{V I}^{\mathrm{d}}$} & \multirow[b]{2}{*}{$\boldsymbol{R}^{2}$} & \multicolumn{2}{|c|}{ AOV rank ${ }^{b}$} \\
\hline & & & SEEy & CV \\
\hline \multirow[t]{8}{*}{ November } & $830 \mathrm{~nm}$ & 4.50 & 7.00 & 6.50 \\
\hline & $830 / 560$ & 2.50 & 4.00 & 3.00 \\
\hline & $830 / 660$ & 2.00 & 3.00 & 2.00 \\
\hline & $1,650 / 830$ & 5.00 & 7.00 & 7.00 \\
\hline & DVI & 3.50 & 4.50 & 4.50 \\
\hline & RDVI & 3.00 & 3.50 & 3.50 \\
\hline & NDVI & 3.50 & 4.00 & 4.50 \\
\hline & GNDVI & 1.50 & 2.00 & 2.00 \\
\hline
\end{tabular}

Table 2. Coefficients of determination $\left(R^{2}\right)$, intercepts, slopes, standard error of the estimate for $y$ (SEEy), and coefficients of variation (CV) for significant $(F \leq 0.0001)$ linear relationships between reflectance measurements and stem height, defoliation severity, and the incidence of stems with ray blight on 6 November 2002 at Sisters Creek

\begin{tabular}{|c|c|c|c|c|c|}
\hline Measurements, W, R, VI ${ }^{\mathbf{a}}$ & $R^{2 \mathrm{~b}}$ & Intercept & Slope & SEEy & CV $(\%)$ \\
\hline \multicolumn{6}{|l|}{ Stem height } \\
\hline $560 \mathrm{~nm}$ & 0.48 & 172.21 & -562.03 & 64.38 & 1.54 \\
\hline $830 \mathrm{~nm}$ & 0.75 & 11.48 & 73.13 & 44.94 & 1.28 \\
\hline $1650 \mathrm{~nm}$ & 0.32 & -115.10 & $1,746.09$ & 73.86 & 1.65 \\
\hline $830 / 485$ & 0.72 & 28.56 & 9.03 & 47.91 & 1.33 \\
\hline $660 / 560$ & 0.57 & $-1,831.45$ & $1,840.28$ & 58.40 & 1.46 \\
\hline $830 / 560$ & 0.76 & 101.59 & -105.33 & 43.67 & 1.26 \\
\hline $1650 / 560$ & 0.59 & -493.50 & $1,359.61$ & 56.84 & 1.44 \\
\hline $830 / 660$ & 0.75 & 52.51 & 67.31 & 44.89 & 1.28 \\
\hline $1650 / 660$ & 0.36 & -551.60 & $1,821.38$ & 71.72 & 1.62 \\
\hline $1650 / 830$ & 0.71 & $-1,373.43$ & 909.04 & 48.31 & 1.33 \\
\hline NDVI & 0.71 & $2,392.19$ & -136.32 & 47.88 & 1.32 \\
\hline GNDVI & 0.77 & $3,618.12$ & $-2,375.92$ & 42.72 & 1.25 \\
\hline DVI & 0.75 & 11.81 & 124.27 & 44.56 & 1.28 \\
\hline RDVI & 0.75 & 128.75 & -139.23 & 45.16 & 1.29 \\
\hline \multicolumn{6}{|l|}{ Defoliation severity } \\
\hline $560 \mathrm{~nm}$ & 0.41 & 277.09 & -35.93 & 15.59 & 7.77 \\
\hline $830 \mathrm{~nm}$ & 0.77 & 154.17 & -2.64 & 9.73 & 6.14 \\
\hline $1650 \mathrm{~nm}$ & 0.35 & -241.44 & 27.49 & 16.30 & 7.95 \\
\hline $830 / 485$ & 0.69 & 165.93 & -6.40 & 11.15 & 6.57 \\
\hline $1650 / 485$ & 0.36 & -88.59 & 28.33 & 16.23 & 7.93 \\
\hline $660 / 560$ & 0.62 & -258.36 & 429.69 & 12.58 & 6.98 \\
\hline $830 / 560$ & 0.84 & 200.44 & -24.21 & 8.05 & 5.59 \\
\hline $1650 / 560$ & 0.57 & -133.95 & 108.93 & 13.36 & 7.19 \\
\hline $830 / 660$ & 0.83 & 159.13 & -12.49 & 8.49 & 5.74 \\
\hline $1650 / 830$ & 0.73 & -38.34 & 316.81 & 10.46 & 6.37 \\
\hline NDVI & 0.78 & 496.09 & -565.12 & 9.61 & 6.10 \\
\hline GNDVI & 0.82 & 728.81 & -846.33 & 8.54 & 5.75 \\
\hline DVI & 0.78 & 142.75 & -2.73 & 9.51 & 6.07 \\
\hline RDVI & 0.78 & 204.21 & -29.84 & 9.52 & 6.07 \\
\hline \multicolumn{6}{|c|}{ Incidence of stems with ray blight } \\
\hline $560 \mathrm{~nm}$ & 0.44 & 325.65 & -45.43 & 18.67 & 10.93 \\
\hline $830 \mathrm{~nm}$ & 0.73 & 162.48 & -3.14 & 13.01 & 9.12 \\
\hline $1650 \mathrm{~nm}$ & 0.36 & -321.77 & 33.99 & 19.87 & 11.27 \\
\hline $830 / 485$ & 0.63 & 173.57 & -7.46 & 15.11 & 9.82 \\
\hline $1650 / 485$ & 0.42 & -144.77 & 37.45 & 18.96 & 11.01 \\
\hline $660 / 560$ & 0.63 & -344.68 & 543.00 & 15.05 & 9.82 \\
\hline $830 / 560$ & 0.77 & 214.87 & -28.37 & 11.91 & 8.73 \\
\hline $1650 / 560$ & 0.59 & -193.31 & 137.28 & 15.74 & 10.03 \\
\hline $830 / 660$ & 0.77 & 167.64 & -14.78 & 11.96 & 8.74 \\
\hline $1650 / 830$ & 0.73 & -69.14 & 386.23 & 12.98 & 9.11 \\
\hline NDVI & 0.75 & 575.82 & -680.63 & 12.44 & 8.92 \\
\hline GNDVI & 0.76 & 838.20 & -996.96 & 12.16 & 8.82 \\
\hline DVI & 0.73 & 148.73 & -3.24 & 12.84 & 9.06 \\
\hline RDVI & 0.74 & 222.67 & -35.63 & 12.67 & 9.00 \\
\hline
\end{tabular}

a Plant and disease measurements, wavelengths $(\mathrm{W})$, ratios $(\mathrm{R})$, and vegetative indices (VI). NDVI = normalized difference vegetative index, GNDVI = green normalized difference vegetative index, DVI $=$ difference vegetative index, and RDVI = renormalized difference vegetative index .

${ }^{\mathrm{b}}$ Regression model shown only when $R^{2}$ is greater than 0.3 and $F$ statistics $=0.0001$.

1.6-m boom with hollow cone nozzles spaced $40 \mathrm{~cm}$ apart. Each plot was $6 \mathrm{~m}$ long and $3.2 \mathrm{~m}$ wide, with 1 -m buffers of nontreated pyrethrum.

Disease intensity and plant density assessments. Disease intensity was assessed visually in each trial within 7 days of the first fungicide application, with further assessments performed at selected dates until harvest (December). At Sisters Creek, visual disease intensity was assessed on 6 October and 6 November. For Table Cape, disease intensity assessments were made on 15 October, 18 November, and 3 December. At Wynyard, disease intensity (visual) was assessed on the same dates as for Table Cape in October and November. Within each plot, 20 flowering stems were selected systematically along a diagonal transect. Each stem was removed from the base of the plant and stored at $4^{\circ} \mathrm{C}$ until visual assessments were performed in the laboratory (within $48 \mathrm{~h}$ ). Stems were assessed in a manner similar to that previously described by Pethybridge et al. (36). In brief, defoliation severity was defined as the height to defoliation (leaves either completely necrotic or abscised) divided by the total stem height $\times 100$. On each stem, the number of diseased and healthy flowers or buds also was counted. This facilitated the calculation of the incidence of stems with ray blight, defined as the number of stems with at least one diseased flower or bud, divided by the total number of stems $\times 100$.

Radiometric assessments. Incident and reflected radiation from pyrethrum canopies was measured with a handheld, multispectral radiometer (MSR5; CropScan Inc., Rochester, $\mathrm{MN}$ ) at five narrow wavelength bands $(485,560,660,830$, and $1,650 \mathrm{~nm})$. At Sisters Creek, canopy reflectance was measured on 6 November. At Table Cape and Wynyard, canopy reflectance measurements were taken on 16 October and 20 November, and an additional measurement was conducted at $\mathrm{Ta}-$ ble Cape on 3 December. The radiometer was positioned $2 \mathrm{~m}$ above the soil, which measured reflectance from a 1-m-diameter area $\left(0.79 \mathrm{~m}^{2}\right)(25,29)$. The edge of a plot was avoided by extending and positioning the sensor over the pyrethrum canopy using an aluminum pole (17). Readings of percent reflectance were obtained between 1100 and 1400 h (Eastern Australian Standard Time) when incoming irradiation was at least 500 watts $/ \mathrm{m}^{2}$. Percent reflectance from the pyrethrum canopy was calculated as a percentage of the voltage value for the reflected radiation divided by the voltage value for the incident radiation at each of the wavelengths. Four readings were taken for each plot at Table Cape and Wynyard, whereas two readings were taken for each plot at Sisters Creek. Readings within plots were averaged to provide a single radiometric reading. The following vegetative indices were calculated: (i) normalized difference vegetative index (NDVI) $\left[\left(\mathrm{R}_{830}\right.\right.$ $\left.\left.-\mathrm{R}_{660}\right) /\left(\mathrm{R}_{830}+\mathrm{R}_{660}\right)\right]$ (13), (ii) green normalized difference vegetative index $\left(\right.$ GNDVI) $\left(\left\{\mathrm{R}_{830}-\left[\left(\mathrm{R}_{485}+\mathrm{R}_{560}\right) / 2\right]\right\} /\left\{\mathrm{R}_{830}\right.\right.$ $\left.\left.+\left[\left(\mathrm{R}_{485}+\mathrm{R}_{560}\right) / 2\right]\right\}\right)$ (15), (iii) difference vegetative index (DVI) $\left\{\mathrm{R}_{830}-\left[\left(\mathrm{R}_{560}+\right.\right.\right.$ $\mathrm{R}_{660}$ )]/2\} (8), and (iv) renormalized difference vegetative index (RDVI) $[\sqrt{ }(\mathrm{NDVI} \times$ DVI)] (8). All possible ratios between individual wavelengths also were calculated.

Data analysis. All data analyses were conducted using Genstat 8 (version 1; 
Adept Scientific Inc., Bethesda, MD). The quantitative relationships of all individual wavelengths, their derived ratios, and vegetative indices with visual disease intensity assessments were screened using linear regression analysis. The primary and secondary criteria used for model selection were the coefficient of determination $\left(R^{2}\right)$ and coefficient of variation $(\mathrm{CV})$, respectively. Other criteria used to assess the goodness-of-fit to each model were the $F$ statistic and the standard error of the estimate for $y$ (SEEy). The coefficient of determination indicates, for example, the proportion of variation in percent reflectance measurements as explained by changes in foliar disease intensity assessments. The SEEy is the square root of the unexplained variation of $y$, providing a measurement of error (precision) associated with predicted values of $y$. Only mod- els with coefficients of determination greater than or equal to 0.3 , with $F$ statistics $=0.0001$, are shown.

To identify the individual wavelength bands, reflectance ratios, and vegetative indices that best quantify relationships with visual disease intensity assessment methods, regression results $\left(R^{2}, \mathrm{CV}\right.$, and SEEy) were summarized using AOV ranks averaged across all three locations for assessment times in October and November.

\section{RESULTS}

Disease intensity. Application of fungicides was effective in obtaining a range of disease intensities (defoliation severity and incidence of stems with ray blight) and plant health measures (stem height and the number of flowers produced on each stem) at all locations. At Sisters Creek, defoliation severity ranged from $5.2 \%( \pm 2.3$,

Table 3. Coefficients of determination $\left(R^{2}\right)$, intercepts, slopes, standard error of the estimate for $y$ (SEEy), and coefficients of variation (CV) for significant $(F \leq 0.0001)$ linear relationships between reflectance measurements on 16 October and plant and disease measurements on 15 October 2004 at Table Cape

\begin{tabular}{|c|c|c|c|c|c|}
\hline Measurements, W, R, VI ${ }^{\mathrm{a}}$ & $R^{2 b}$ & Intercept & Slope & SEEy & $\mathrm{CV}(\%)$ \\
\hline \multicolumn{6}{|l|}{ Stem height } \\
\hline $830 \mathrm{~nm}$ & 0.68 & -24.47 & 1.09 & 5.18 & 6.22 \\
\hline $660 / 560$ & 0.51 & 163.25 & -180.43 & 6.38 & 6.90 \\
\hline $830 / 560$ & 0.69 & -41.75 & 11.06 & 5.06 & 6.15 \\
\hline $1,650 / 560$ & 0.41 & 162.39 & -70.36 & 6.98 & 7.22 \\
\hline $830 / 660$ & 0.66 & -13.99 & 4.98 & 5.33 & 6.31 \\
\hline $1,650 / 830$ & 0.62 & 89.28 & -206.33 & 5.62 & 6.48 \\
\hline NDVI & 0.62 & -211.61 & 303.47 & 5.58 & 6.46 \\
\hline GNDVI & 0.31 & -89.62 & 157.29 & 7.56 & 7.52 \\
\hline DVI & 0.68 & -17.89 & 1.11 & 5.14 & 6.19 \\
\hline RDVI & 0.67 & -53.97 & 14.33 & 5.17 & 6.22 \\
\hline \multicolumn{6}{|l|}{ Defoliation severity } \\
\hline $830 \mathrm{~nm}$ & 0.62 & 209.62 & -2.87 & 15.16 & 7.81 \\
\hline $660 / 560$ & 0.62 & -330.79 & 542.21 & 15.27 & 7.84 \\
\hline $830 / 560$ & 0.71 & 266.62 & -30.59 & 13.24 & 7.29 \\
\hline $1,650 / 560$ & 0.50 & -328.11 & 211.39 & 17.50 & 8.39 \\
\hline $830 / 660$ & 0.70 & 191.97 & -13.98 & 13.58 & 7.39 \\
\hline $1,650 / 830$ & 0.69 & -102.14 & 595.15 & 13.69 & 7.42 \\
\hline NDVI & 0.70 & 767.76 & -877.76 & 13.47 & 7.36 \\
\hline DVI & 0.64 & 193.49 & -2.93 & 14.87 & 7.73 \\
\hline RDVI & 0.66 & 293.20 & -38.51 & 14.44 & 7.67 \\
\hline \multicolumn{6}{|l|}{ Number of flowers/stem } \\
\hline $830 \mathrm{~nm}$ & 0.46 & -6.16 & 0.16 & 1.15 & 41.55 \\
\hline $660 / 560$ & 0.32 & 19.93 & -24.71 & 1.29 & 44.11 \\
\hline $830 / 560$ & 0.47 & -8.54 & 1.57 & 1.15 & 41.51 \\
\hline $1,650 / 560$ & 0.31 & 21.51 & -10.58 & 1.31 & 44.24 \\
\hline $830 / 660$ & 0.43 & -4.46 & 0.69 & 1.19 & 42.26 \\
\hline $1,650 / 830$ & 0.44 & 10.25 & -30.04 & 1.18 & 42.04 \\
\hline NDVI & 0.42 & -32.61 & 43.03 & 1.19 & 42.39 \\
\hline DVI & 0.47 & -5.21 & 0.16 & 1.15 & 41.52 \\
\hline RDVI & 0.46 & -10.37 & 2.05 & 1.15 & 41.56 \\
\hline \multicolumn{6}{|c|}{ Incidence of stems with ray blight } \\
\hline $660 \mathrm{~nm}$ & 0.35 & -256.54 & 52.52 & 18.23 & 13.33 \\
\hline $830 \mathrm{~nm}$ & 0.41 & 150.88 & -2.14 & 17.36 & 13.00 \\
\hline $660 / 560$ & 0.51 & -282.53 & 448.08 & 15.94 & 12.46 \\
\hline $830 / 560$ & 0.51 & 200.29 & -23.74 & 15.79 & 12.90 \\
\hline $1650 / 560$ & 0.43 & -289.68 & 179.93 & 17.07 & 12.89 \\
\hline $830 / 660$ & 0.53 & 144.89 & -11.11 & 15.59 & 12.32 \\
\hline $1,650 / 830$ & 0.52 & -88.49 & 471.95 & 15.68 & 12.36 \\
\hline NDVI & 0.52 & 598.12 & -692.14 & 15.65 & 12.35 \\
\hline DVI & 0.43 & 139.71 & -2.19 & 17.12 & 12.91 \\
\hline RDVI & 0.45 & 215.41 & -29.02 & 16.84 & 12.80 \\
\hline
\end{tabular}

a Plant and disease measurements, wavelengths (W), ratios (R), and vegetative indices (VI). NDVI = normalized difference vegetative index, GNDVI $=$ green normalized difference vegetative index, DVI $=$ difference vegetative index, and RDVI $=$ renormalized difference vegetative index.

${ }^{\mathrm{b}}$ Regression model shown only when $R^{2}$ is greater than 0.3 and $F$ statistics $=0.0001$.

standard error) to $47 \%( \pm 10.1)$ in October. One month later, defoliation severity ranged from $16.7 \%( \pm 4.4)$ to $63.9 \%( \pm 4.4)$. The height of stems varied between 44.5 $\mathrm{cm}( \pm 23)$ and $66.5 \mathrm{~cm}( \pm 40.8)$, and incidence of stems with ray blight between $0.2 \%( \pm 0.2)$ and $62 \%( \pm 14.9)$.

At Table Cape, defoliation severity ranged in October from $9 \%( \pm 3.2)$ to $77.3 \%( \pm 10.9)$. In October, stem height, the number of flowers produced on each stem, and incidence of stems with ray blight ranged from $28.6 \mathrm{~cm}( \pm 2.9)$ to 53.9 $\mathrm{cm}( \pm 2.4), 1.5( \pm 1.3)$ to $5.2( \pm 1.4)$, and 0 to $50.7 \%( \pm 11.4)$, respectively. Similar ranges in disease intensity and plant health measures also were found in November.

At Wynyard, defoliation severity varied between $3.3 \%( \pm 2.2)$ and $70.1 \%( \pm 4.5)$ in October and $23.8 \%( \pm 10.5)$ and $50.3 \%$ $( \pm 11.3)$ in November. The incidence of stems with ray blight varied from 0 to $39.3 \%( \pm 8.4)$ in October and $18.6 \%( \pm 13)$ in November. Plant health measures also varied greatly from the application of fungicides. For example, stem height and the numbers of flowers produced on each stem ranged between $23.4 \mathrm{~cm}( \pm 2.6)$ and 50.1 $\mathrm{cm}( \pm 3.6)$, and $2( \pm 0.3)$ and $5.8( \pm 1.9)$, respectively, in October. In November, stem height varied between $63.3 \mathrm{~cm}( \pm 4.4)$ and $79.4 \mathrm{~cm}( \pm 4.4)$, and the number of flowers produced on each stem ranged between $4.1( \pm 1)$ and $6.8( \pm 4.3)$.

Relationships between canopy reflectance and foliar disease intensity. Selection of the best individual wavelength band, reflectance ratios, and vegetative indices for remote assessment of disease intensity, stem height, and the number of flowers produced on each stem varied with time (Table 1). In October, AOV ranks and the distance between the best ranking and actual regression model statistics were consistently lowest using the ratio 830/560 for assessment of stem height, defoliation severity, and the number of flowers produced on each stem. In November, reflectance at $830 \mathrm{~nm}$ and the DVI were superior (ranked lower) for these measures. However, reflectance in the near-infrared region $(830 \mathrm{~nm})$ was a poor predictor of the incidence of stems with ray blight compared with other wavelength bands, ratios, and vegetative indices at all times. For the incidence of stems with ray blight, $1,650 / 830$ was ranked marginally higher than 830/560 in October whereas, in November, GNDVI was ranked lower (better) than the DVI and RDVI (Table 1).

Sisters Creek. Reflectance measurements of $830 \mathrm{~nm}, 830 / 560,830 / 660$, $1,650 / 830$, and all vegetative indices taken in November had the strongest relationships with stem height $\left(R^{2}=0.71\right.$ to 0.77$)$, defoliation severity $\left(R^{2}=0.73\right.$ to 0.84$)$, and incidence of stems with ray blight $\left(R^{2}\right.$ $=0.73$ to 0.77 ). Furthermore, all of these models had coefficients of variation less than $10 \%$ (Table 2). 
Table Cape. The reflectance measurements for $830 \mathrm{~nm}, 660 / 560,830 / 560$, $1,650 / 560,830 / 660,1,650 / 830$, NDVI, DVI, and RDVI in October had the strongest linear relationships with stem height $\left(R^{2}=0.41\right.$ to 0.69$)$, defoliation severity $\left(R^{2}\right.$ $=0.50$ to 0.71$)$, the number of flowers produced on each stem $\left(R^{2}=0.31\right.$ to 0.47$)$, and incidence of stems with ray blight $\left(R^{2}\right.$ $=0.41$ to 0.53 ). The coefficients of variation were less than $10 \%$ for these significant models using stem height and defoliation severity. However, for models using the number of flowers produced on each stem and incidence of stems with ray blight, coefficients of variation were approximately four and two times higher than for stem height and defoliation severity, respectively (Table 3 ). The reflectancebased measurements in October also had strong linear relationships with plant and disease measurements in November (Table 4 ), with coefficients of determination varying from 0.56 to 0.70 (stem height), 0.48 to 0.69 (defoliation severity), and 0.45 to 0.73 (number of flowers produced on each stem). These reflectance measurements in October, with the exception of 1,650/560, also were related linearly to the incidence of stems with ray blight in October $\left(R^{2}=\right.$ 0.32 to 0.39 ) (Table 3 ). Similar relationships also were depicted between these reflectance measurements in November and plant and disease measurements performed for the same dates (Table 4), with coefficients of determination ranging from 0.41 to 0.63 (stem height), 0.37 to 0.65 (defoliation severity), and 0.41 to 0.69 (number of flowers produced on each stem). With the exception of 660/560, $1,650 / 560$, and $1650 / 830$, these same reflectance measures in November also were related in a linear fashion to the incidence of stems with ray blight in November $\left(R^{2}=\right.$ 0.34 to 0.39 ; Table 4 ). Some individual reflectance measurements also had strong linear relationships with some, but not all, plant and disease measurements. For example, $1,650 \mathrm{~nm}$ in November, but not October, had a strong linear relationship with stem height, defoliation severity, and number of flowers produced on each stem. Similarly, GNDVI calculated from reflectance measurements in November had a strong linear relationship with the incidence of stems with ray blight (Table 4). Coefficients of variation for the significant models were consistently low for stem height (less than $10 \%$ in both October and November). Moreover, for defoliation severity, coefficients of variation in October were approximately double those of significant models in November (Table 4).

Wynyard. Reflectance measurements at $830 \mathrm{~nm}, 830 / 560,830 / 660,1,650 / 830$, NDVI, DVI, and RDVI in October were linearly related to stem height, defoliation severity, the number of flowers produced on each stem, and the incidence of stems with ray blight in October with coefficients
Table 4. Coefficients of determination $\left(R^{2}\right)$, intercepts, slopes, standard error of the estimate for $y$ (SEEy), and coefficients of variation $(\mathrm{CV})$ for significant $(F \leq 0.0001)$ linear relationships between reflectance measurements on 16 October and 20 November and plant and disease measurements on 18 November 2004 at Table Cape

\begin{tabular}{|c|c|c|c|c|c|}
\hline Measurements, date, W, R, VI ${ }^{\mathrm{a}}$ & $R^{2 b}$ & Intercept & Slope & SEEy & $\mathrm{CV}(\%)$ \\
\hline \multicolumn{6}{|l|}{ Stem height } \\
\hline \multicolumn{6}{|l|}{16 October } \\
\hline $660 \mathrm{~nm}$ & 0.39 & 223.94 & -30.09 & 9.55 & 5.28 \\
\hline $830 \mathrm{~nm}$ & 0.56 & -16.52 & 1.35 & 8.12 & 4.87 \\
\hline $660 / 560$ & 0.66 & 253.74 & -277.99 & 7.13 & 4.56 \\
\hline $830 / 560$ & 0.67 & -45.63 & 14.71 & 7.04 & 4.53 \\
\hline $1,650 / 560$ & 0.58 & 261.53 & -113.49 & 7.89 & 4.79 \\
\hline $830 / 660$ & 0.68 & -10.92 & 6.84 & 6.94 & 4.49 \\
\hline $1,650 / 830$ & 0.70 & 134.31 & -296.50 & 6.72 & 4.42 \\
\hline NDVI & 0.69 & -295.33 & 432.73 & 6.77 & 4.44 \\
\hline DVI & 0.58 & -9.26 & 1.39 & 7.95 & 4.82 \\
\hline RDVI & 0.61 & -57.12 & 18.31 & 7.69 & 4.74 \\
\hline \multicolumn{6}{|l|}{20 November } \\
\hline $830 \mathrm{~nm}$ & 0.60 & -0.80 & 1.69 & 7.72 & 4.74 \\
\hline $1650 \mathrm{~nm}$ & 0.46 & 141.49 & -6.74 & 9.02 & 5.13 \\
\hline $660 / 560$ & 0.49 & 265.19 & -215.31 & 8.69 & 5.03 \\
\hline $830 / 560$ & 0.44 & -1.34 & 17.89 & 9.17 & 5.17 \\
\hline $1,650 / 560$ & 0.41 & 105.89 & -39.77 & 9.44 & 5.24 \\
\hline $830 / 660$ & 0.49 & 9.13 & 14.09 & 8.79 & 5.06 \\
\hline $1,650 / 660$ & 0.32 & 110.77 & -42.25 & 10.09 & 5.42 \\
\hline $1,650 / 830$ & 0.58 & 96.27 & -103.48 & 7.94 & 4.81 \\
\hline NDVI & 0.46 & -17.88 & 139.26 & 9.03 & 5.13 \\
\hline GNDVI & 0.30 & 1.37 & 102.02 & 10.64 & 5.57 \\
\hline DVI & 0.63 & 12.23 & 1.87 & 7.42 & 4.65 \\
\hline RDVI & 0.61 & -3.32 & 16.83 & 7.67 & 4.73 \\
\hline \multicolumn{6}{|l|}{ Defoliation severity } \\
\hline \multicolumn{6}{|l|}{16 October } \\
\hline $660 \mathrm{~nm}$ & 0.38 & -303.40 & 64.52 & 20.98 & 40.43 \\
\hline $830 \mathrm{~nm}$ & 0.56 & 214.76 & -2.94 & 17.65 & 38.20 \\
\hline $660 / 560$ & 0.61 & -355.07 & 578.62 & 16.76 & 37.03 \\
\hline $830 / 560$ & 0.69 & 281.38 & -32.49 & 14.83 & 35.48 \\
\hline $1,650 / 560$ & 0.48 & -347.17 & 222.77 & 19.31 & 35.31 \\
\hline $830 / 660$ & 0.69 & 203.18 & -14.96 & 14.93 & 30.92 \\
\hline $1,650 / 830$ & 0.65 & -107.63 & 621.67 & 15.79 & 33.64 \\
\hline NDVI & 0.67 & 806.00 & -922.94 & 15.38 & 32.89 \\
\hline DVI & 0.58 & 199.05 & -3.02 & 17.26 & 36.99 \\
\hline RDVI & 0.60 & 301.71 & -39.65 & 16.87 & 37.44 \\
\hline \multicolumn{6}{|l|}{20 November } \\
\hline $830 \mathrm{~nm}$ & 0.63 & 182.63 & -3.75 & 16.34 & 13.89 \\
\hline $1,650 \mathrm{~nm}$ & 0.39 & -115.03 & 13.51 & 20.85 & 17.08 \\
\hline $660 / 560$ & 0.46 & -379.73 & 449.03 & 19.64 & 19.82 \\
\hline $830 / 560$ & 0.44 & 181.50 & -38.93 & 19.96 & 21.51 \\
\hline $1,650 / 560$ & 0.37 & -46.29 & 81.93 & 21.26 & 20.59 \\
\hline $830 / 660$ & 0.48 & 158.24 & -30.50 & 19.23 & 20.53 \\
\hline $1,650 / 830$ & 0.53 & -27.15 & 215.02 & 18.30 & 22.82 \\
\hline NDVI & 0.44 & 214.06 & -296.71 & 19.98 & 25.01 \\
\hline GNDVI & 0.39 & 192.47 & -252.97 & 21.58 & 27.44 \\
\hline DVI & 0.65 & 153.35 & -4.13 & 15.78 & 26.64 \\
\hline RDVI & 0.61 & 185.91 & -36.64 & 16.68 & 29.10 \\
\hline \multicolumn{6}{|l|}{ Number of flowers/stem } \\
\hline \multicolumn{6}{|l|}{16 October } \\
\hline $830 \mathrm{~nm}$ & 0.63 & -14.35 & 0.39 & 2.03 & 19.09 \\
\hline $660 / 560$ & 0.58 & 57.42 & -71.17 & 2.17 & 19.75 \\
\hline $830 / 560$ & 0.73 & -22.34 & 4.21 & 1.73 & 17.62 \\
\hline $1650 / 560$ & 0.45 & 55.86 & -27.07 & 2.49 & 21.17 \\
\hline $830 / 660$ & 0.72 & -12.05 & 1.92 & 1.78 & 17.89 \\
\hline $1,650 / 830$ & 0.65 & 27.41 & -78.11 & 1.98 & 18.87 \\
\hline NDVI & 0.67 & -87.55 & 116.17 & 1.92 & 18.58 \\
\hline DVI & 0.65 & -12.17 & 0.40 & 1.98 & 18.88 \\
\hline RDVI & 0.66 & -25.43 & 5.21 & 1.97 & 18.79 \\
\hline \multicolumn{6}{|l|}{20 November } \\
\hline $830 \mathrm{~nm}$ & 0.68 & -9.72 & 0.49 & 1.91 & 18.49 \\
\hline $1,650 \mathrm{~nm}$ & 0.41 & 28.75 & -1.73 & 2.58 & 21.55 \\
\hline $660 / 560$ & 0.47 & 62.13 & -56.97 & 2.44 & 20.96 \\
\hline \multirow[t]{2}{*}{$830 / 560$} & 0.45 & -9.06 & 4.93 & 2.49 & 21.14 \\
\hline & & & \multicolumn{3}{|c|}{ (continued on next page) } \\
\hline
\end{tabular}

a Plant and disease measurements on 18 November, date of reflectance measurements, and wavelengths (W), ratios (R), and vegetative indices (VI). NDVI = normalized difference vegetative index, GNDVI = green normalized difference vegetative index, DVI $=$ difference vegetative index, and RDVI = renormalized difference vegetative index.

b Regression model shown only when $R^{2}$ is greater than 0.3 and $F$ statistics $=0.0001$. 
Table 4. (continued from preceding page)

\begin{tabular}{lrrrrr}
\hline Measurements, date, $\mathbf{W}, \mathbf{R}, \mathbf{V I}^{\mathbf{a}}$ & $\boldsymbol{R}^{\mathbf{2 b}}$ & Intercept & Slope & SEEy & $\mathbf{C V}(\boldsymbol{\%})$ \\
\hline $1,650 / 560$ & 0.34 & 20.24 & -10.75 & 2.59 & 21.61 \\
$830 / 660$ & 0.49 & -6.13 & 3.87 & 2.39 & 20.73 \\
1,650/660 & 0.33 & 21.82 & -11.63 & 2.75 & 22.23 \\
1,650/830 & 0.55 & 17.51 & -27.59 & 2.24 & 20.06 \\
NDVI & 0.45 & -13.19 & 37.63 & 2.49 & 21.15 \\
GNDVI & 0.35 & -8.86 & 29.03 & 2.76 & 22.27 \\
DVI & 0.69 & -5.83 & 0.54 & 1.84 & 18.19 \\
RDVI & 0.64 & -9.92 & 4.72 & 2.00 & 18.98 \\
Incidence of stems with ray blight & & & & \\
16 October & & & & \\
830 nm & 0.32 & 215.45 & -3.19 & 31.45 & 14.96 \\
660/560 & 0.36 & -412.57 & 641.07 & 30.56 & 14.74 \\
830/560 & 0.39 & 288.34 & -35.40 & 29.64 & 14.52 \\
830/660 & 0.39 & 202.49 & -16.24 & 29.78 & 14.55 \\
1,650/830 & 0.36 & -130.67 & 658.43 & 30.72 & 14.78 \\
NDVI & 0.39 & 873.03 & $-1,021.60$ & 29.67 & 14.53 \\
DVI & 0.34 & 198.36 & -3.29 & 31.19 & 14.89 \\
RDVI & 0.35 & 311.72 & -43.39 & 30.84 & 14.81 \\
20 November & & & & & 14.88 \\
830 nm & 0.34 & 175.81 & -3.95 & 31.15 & 14.88 \\
830/560 & 0.34 & 200.67 & -48.74 & 31.17 & 14.80 \\
830/660 & 0.35 & 168.62 & -37.35 & 30.82 & 14.88 \\
NDVI & 0.34 & 242.19 & -372.83 & 31.13 & 12.92 \\
GNDVI & 0.51 & 226.62 & -343.33 & 23.46 & 14.59 \\
DVI & 0.39 & 150.36 & -4.56 & 29.97 & 14.57 \\
RDVI & 0.39 & 192.34 & -42.11 & 29.84 & \\
\hline
\end{tabular}

Table 5. Coefficients of determination $\left(R^{2}\right)$, intercepts, slopes, standard error of the estimate for $y$ (SEEy), and coefficients of variation $(\mathrm{CV})$ for significant $(F \leq 0.0001)$ linear relationships between plant and disease measurements on 15 October and reflectance measurements on 16 October 2004 at Wynyard

\begin{tabular}{|c|c|c|c|c|c|}
\hline Measurements, W, R, VI ${ }^{\mathbf{a}}$ & $R^{2 b}$ & Intercept & Slope & SEEy & CV (\%) \\
\hline \multicolumn{6}{|l|}{ Stem height } \\
\hline 830 & 0.62 & -58.91 & 1.40 & 6.33 & 7.23 \\
\hline $660 / 560$ & 0.33 & 408.92 & -587.17 & 8.37 & 8.32 \\
\hline $830 / 560$ & 0.65 & -81.94 & 14.51 & 6.06 & 7.08 \\
\hline $830 / 660$ & 0.63 & -63.17 & 7.75 & 6.24 & 7.18 \\
\hline $1,650 / 830$ & 0.61 & 137.35 & -492.24 & 6.36 & 7.25 \\
\hline NDVI & 0.62 & -577.25 & 718.04 & 6.27 & 7.19 \\
\hline GNDVI & 0.37 & -254.27 & 358.41 & 8.11 & 8.18 \\
\hline DVI & 0.62 & -51.32 & 1.44 & 6.27 & 7.19 \\
\hline RDVI & 0.62 & -115.86 & 21.13 & 6.27 & 7.19 \\
\hline \multicolumn{6}{|l|}{ Defoliation severity } \\
\hline 830 & 0.58 & 282.80 & -3.61 & 17.33 & 9.79 \\
\hline $830 / 560$ & 0.63 & 346.56 & -37.79 & 16.27 & 9.49 \\
\hline $830 / 660$ & 0.61 & 296.25 & -20.07 & 16.87 & 9.66 \\
\hline $1,650 / 830$ & 0.59 & -222.86 & $1,273.79$ & 17.19 & 9.75 \\
\hline NDVI & 0.58 & $1,604.09$ & $-1,831.99$ & 17.33 & 9.79 \\
\hline GNDVI & 0.32 & 755.45 & -881.79 & 22.14 & 11.06 \\
\hline DVI & 0.59 & 263.65 & -3.70 & 17.16 & 9.74 \\
\hline RDVI & 0.59 & 428.03 & -54.07 & 17.26 & 9.77 \\
\hline \multicolumn{6}{|l|}{ Number of flowers/stem } \\
\hline 830 & 0.30 & -7.49 & 0.15 & 1.34 & 41.73 \\
\hline $830 / 560$ & 0.44 & -12.31 & 1.88 & 1.19 & 39.46 \\
\hline $830 / 660$ & 0.39 & -9.32 & 0.96 & 1.25 & 40.35 \\
\hline $1,650 / 830$ & 0.38 & 15.33 & -60.27 & 1.26 & 40.59 \\
\hline NDVI & 0.36 & -69.49 & 84.77 & 1.29 & 40.92 \\
\hline DVI & 0.31 & -6.80 & 0.16 & 1.32 & 41.54 \\
\hline RDVI & 0.31 & -13.91 & 2.34 & 1.33 & 41.58 \\
\hline \multicolumn{6}{|c|}{ Incidence of stems with ray blight } \\
\hline 830 & 0.38 & 155.17 & -1.97 & 14.38 & 16.05 \\
\hline $830 / 560$ & 0.43 & 193.55 & -21.12 & 13.79 & 15.72 \\
\hline $830 / 660$ & 0.39 & 162.93 & -11.02 & 14.19 & 15.94 \\
\hline $1,650 / 830$ & 0.51 & -143.59 & 802.64 & 12.79 & 15.13 \\
\hline NDVI & 0.39 & 890.36 & $-1,016.82$ & 14.26 & 15.97 \\
\hline DVI & 0.39 & -2.03 & -2.03 & 14.31 & 16.00 \\
\hline RDVI & 0.39 & -29.69 & -29.69 & 14.33 & 16.02 \\
\hline
\end{tabular}

a Plant and disease measurements on 15 October and wavelengths (W), ratios (R), and vegetative indices (VI) on 16 October. NDVI = normalized difference vegetative index, GNDVI = green normalized difference vegetative index, DVI = difference vegetative index, and RDVI = renormalized difference vegetative index.

${ }^{\text {b }}$ Regression model shown only when $R^{2}$ is greater than 0.3 and $F$ statistics $=0.0001$. of determination ranging from 0.61 to $0.65,0.58$ to $0.63,0.31$ to 0.44 , and 0.38 to 0.51 , respectively. Reflectance measurements at 660/560 and the GNDVI also both were related to stem height, and the GNDVI to defoliation severity, but the relationship had lower $R^{2}$ than other measurements. Coefficients of variation for significant models using stem height and defoliation severity usually were less than $10 \%$ whereas, for models using the number of flowers produced on each stem, they were approximately four times higher (Table 5).

Reflectance measurements at $830 \mathrm{~nm}$, 830/560, 830/660, 1,650/830, NDVI, DVI, and RDVI made in October that were related to stem height in October were also, with the addition of 660/560 and the GNDVI, related to stem height in November $\left(R^{2}=0.36\right.$ to 0.49 ; Table 6$)$. However, of the reflectance measurements obtained in November, only $830 \mathrm{~nm}, 1,650 / 830$, and the DVI had a moderate relationship $\left(R^{2}=\right.$ 0.37 to 0.42 ) with stem height. All reflectance measurements in October were poor predictors of defoliation severity assessments also obtained in November (Table 6) and, of those recorded in November, only $830 \mathrm{~nm}, 1,650 / 830$, DVI, and RDVI had linear relationships with defoliation severity in November $\left(R^{2}=0.33\right.$ to 0.41$)$. All reflectance measurements in October or November had no or weak $\left(R^{2}<0.30\right)$ relationships to the number of flowers produced on each stem in November. Some reflectance measurements in October were moderately linearly related to the incidence of stems with ray blight in November $\left(R^{2}=0.31\right.$ to 0.38 ; Table 6$)$. However, all reflectance measurements in November had weak $\left(R^{2}<0.30\right)$ or no relationships with the incidence of stems with ray blight in November. Coefficients of variation again were low for models using stem height (less than 4\%) and defoliation severity (less than 10\%), but were approximately $45 \%$ for models using the incidence of stems with ray blight (Table 6).

Consistency of radiometric assessments. Table Cape. The reflectance measurements of $830 \mathrm{~nm}, 660 / 560,1,650 / 560$, 1,650/830, DVI, and RDVI consistently had the strongest linear relationship between themselves over all three time periods (Table 7). The coefficients of determination from 1,650/830 were consistently highest. However the measurements of 1,650/830, 660/560, 1,650/560, and RDVI generally had higher coefficients of variation than $830 \mathrm{~nm}$ and DVI (Table 7). For some measurements, such as 830/660 and NDVI, there was a good relationship between reflectance measurements taken in October and November, but a poor relationship between measurements in October and December, or November and December (Table 7), indicating a lack of consistency over the growing season. Only significant models using $830 \mathrm{~nm}$ and the DVI 
had coefficients of variation less than $10 \%$. Furthermore, models using $830 \mathrm{~nm}$ had coefficients of variation less than 5\%, whereas models using the DVI were slightly higher (Table 7).

Wynyard. The reflectance measurements with the strongest linear relationship between themselves over the two measurement dates were $830 \mathrm{~nm}, 830 / 560$, 830/660, 1,650/830, DVI, and RDVI (Table 8$)$. Although the ratio $1,650 / 830$ had the highest coefficient of determination, it also had a higher coefficient of variation $(>10 \%)$ than other measurements (Table 8). Measurements at $830 \mathrm{~nm}$ and DVI had the lowest coefficients of variation (less than 4\%), similar to the trial at Table Cape.

\section{DISCUSSION}

This study has demonstrated that radiometric measurement of canopy reflectance can be used effectively to quantify disease intensities within pyrethrum crops in Tasmanian fields. Pyrethrum production requires multiple assessments of disease intensities over time not only to assess the efficacy of fungicides but also to evaluate the efficacy of other management tactics that improve the pyrethrum crop and production. Current assessment sampling programs employed from October until harvest in December require the destructive removal of the flowering stem (36). However, these processes can cause considerable crop damage, which is unacceptable to producers.

Ideally, disease assessment systems should be (i) reliable (precise and reproducible), (ii) easy to use, (iii) applicable over a wide range of conditions and times, (iv) fast, (v) accurate, and (vi) related to yield $(9,14,31,35,44)$. Our research addresses primarily criteria (i) through (iv), with relatedness to yield (vi) yet to be studied. Accuracy (v) requires a standard measure of "truth" with which to evaluate all assessment methods (30). As with many pathosystems, a method to obtain a standard measure regarded as the truth is not presently available for the pyrethrum-ray blight pathosystem.

The assessment method of choice (e.g., incidence, severity, percent reflectance of sunlight for a single wavelength band, ratio of two wavelengths, or a vegetation index) must be useful. That is, an assessment method must have the ability to statistically distinguish the efficacy of different fungicides on crop health $(1-Y)$ or the disease intensity $(Y)$ of the crop, where 1 $Y$ is a measure of the healthy plant tissue not yet diseased. For example, the 485-nm wavelength band was a poor predictor of disease intensity or crop health $(P$ values were not significant in all trials and all CVs were above $10 \%$, except for one trial). Thus, percent reflectance values from pyrethrum canopies in the 485-nm wavelength band could not be used to assess ray blight disease intensity or assess crop health.
Necrotic symptoms due to P. ligulicola, which primarily occur from September until harvest in December, decrease green leaf area and reduce the proportion of photosynthetically active tissue available to intercept light (36). Visual disease intensity assessments are often difficult to perform and do not account for reductions in green leaf area index (GLAI) due to plant growth that is slowed or even stopped in response to disease or stress $(18,23,30)$. However, radiometric methods do account for reductions in GLAI because there is a high correlation between percent reflectance values and GLAI. Plant growth has been demonstrated to be proportional to the amount of radiation intercepted by plant canopies, especially at crucial stages of plant development $(13,17,18)$. Previous research on the temporal dynamics in foliar disease intensity and stem growth of the P. ligulicola-pyrethrum pathosystem indicate that August and September were the most likely critical infection period, with maximum disease intensity occurring around mid-October $(36,38)$.

Necrotic lesions, such as those caused by $P$. ligulicola from September through December (harvest), can severely reduce radiation interception by removing healthy green leaf area and by inducing premature defoliation $(19,47)$. Although measures of disease intensity can be assessed visually, remote sensing can account for the impact of plant disease on other, less readily visualized variables that affect plant development. For example, disease intensity early in the season can affect ensuing crop development (fewer main stems, fewer branches, less dense canopy, and so on), thus reducing the absolute amount of green leaf area available to the crop to produce photosynthate for yield $(19,31,47)$. Because disease assessments cannot be performed on plant parts that don't develop due to disease, visual assessment methods do not adequately quantify such effects. However, because reflectance measurements (e.g., $830 \mathrm{~nm}$ ) were related to plant health assessments in our study as well as being strongly related to healthy GLAI in other studies $(23,31)$, disease effects on GLAI (i.e., $1-Y$ ) can be measured. Guan and Nutter (17), Moreira (23), and Nutter et al. (35), also have previously shown that the higher the percent reflectance in the near-infrared bandwidths, the higher the GLAI and the healthier the crop canopy. Reflectance values in the near infrared also have been found to have a strong relation-

Table 6. Coefficients of determination $\left(R^{2}\right)$, intercepts, slopes, standard error of the estimate for $y$ (SEEy), and coefficients of variation $(\mathrm{CV})$ for significant $(F \leq 0.0001)$ linear relationships between reflectance measurements on 16 October and 20 November and plant and disease measurements on 18 November 2004 at Wynyard

\begin{tabular}{|c|c|c|c|c|c|}
\hline Measurements, date, W, R, VIa & $R^{2 b}$ & Intercept & Slope & SEEy & CV (\%) \\
\hline \multicolumn{6}{|l|}{ Stem height } \\
\hline \multicolumn{6}{|l|}{16 October } \\
\hline $830 \mathrm{~nm}$ & 0.48 & -0.99 & 1.08 & 6.36 & 3.56 \\
\hline $660 / 560$ & 0.45 & 451.36 & -597.37 & 6.53 & 3.61 \\
\hline $830 / 560$ & 0.40 & -8.60 & 9.87 & 6.85 & 3.69 \\
\hline $830 / 660$ & 0.43 & 0.32 & 5.57 & 6.66 & 3.65 \\
\hline $1,650 / 830$ & 0.47 & 148.39 & -372.67 & 6.44 & 3.59 \\
\hline NDVI & 0.47 & -388.97 & 539.33 & 6.44 & 3.59 \\
\hline GNDVI & 0.36 & -174.76 & 303.67 & 7.10 & 3.77 \\
\hline DVI & 0.48 & 5.44 & 1.09 & 6.38 & 3.57 \\
\hline RDVI & 0.49 & -44.62 & 16.18 & 6.33 & 3.56 \\
\hline \multicolumn{6}{|l|}{20 November } \\
\hline $830 \mathrm{~nm}$ & 0.42 & -7.87 & 1.73 & 6.45 & 3.69 \\
\hline $1,650 / 830$ & 0.39 & 122.72 & -249.06 & 6.92 & 3.72 \\
\hline DVI & 0.37 & 7.59 & 1.64 & 7.03 & 3.75 \\
\hline RDVI & 0.30 & -17.09 & 16.19 & 7.39 & 3.84 \\
\hline \multicolumn{6}{|l|}{ Defoliation severity } \\
\hline \multicolumn{6}{|l|}{20 November } \\
\hline $830 \mathrm{~nm}$ & 0.41 & 175.37 & -3.01 & 11.94 & 8.97 \\
\hline $1,650 / 830$ & 0.39 & -53.81 & 442.39 & 12.06 & 9.02 \\
\hline DVI & 0.38 & 150.86 & -2.91 & 12.24 & 9.01 \\
\hline RDVI & 0.33 & 200.19 & -29.79 & 12.70 & 9.26 \\
\hline \multirow{2}{*}{\multicolumn{6}{|c|}{$\begin{array}{l}\text { Incidence of stems with ray blight } \\
16 \text { October }\end{array}$}} \\
\hline & & & & & \\
\hline $830 \mathrm{~nm}$ & 0.32 & 104.14 & -1.45 & 12.09 & 46.38 \\
\hline $660 / 560$ & 0.38 & -565.71 & 899.66 & 11.59 & 45.39 \\
\hline $1,650 / 830$ & 0.36 & -105.77 & 543.67 & 11.69 & 45.60 \\
\hline NDVI & 0.32 & 634.19 & -735.21 & 12.11 & 46.39 \\
\hline GNDVI & 0.36 & 419.49 & -509.57 & 11.69 & 45.59 \\
\hline DVI & 0.31 & 95.19 & -1.47 & 12.14 & 46.45 \\
\hline RDVI & 0.33 & 163.63 & -21.89 & 12.04 & 46.27 \\
\hline
\end{tabular}

a Plant and disease measurements on 18 November, date of reflectance measurements, and wavelengths (W), ratios (R), and vegetative indices (VI). NDVI = normalized difference vegetative index, GNDVI = green normalized difference vegetative index, DVI = difference vegetative index, and RDVI = renormalized difference vegetative index.

b Regression model shown only when $R^{2}$ is greater than 0.3 and $F$ statistics $=0.0001$. 
ship with yield of alfalfa (17), barley (27), peanut $(34,35)$, and soybean (23). As predicted by Waggoner and Berger (47), there also often are stronger relationships between GLAI and yield than between visual disease intensity assessments and yield $(17,23,28,31,34)$.

It has been proposed that information from two different wavelength bands expressed as a ratio might have greater precision than reflectance values from single wavelength bands, especially for data obtained from different locations and at different times (42). In our study, combining reflectance within the near-infrared range with the 560-nm wavelength band
(830/560) was superior to all other measures in October for remote assessment of stem height, defoliation severity, and the number of flowers produced on each stem. However, this ratio was inferior to the 830$\mathrm{nm}$ single-wavelength band and the DVI in November. Chronological age has been noted to influence spectral reflectance from corn leaves. Bausch and Duke (6) observed that new leaves reflect more green light compared with older leaves (560-nm wavelength band) because they were not uniformly green when emerging from the whorl. In pyrethrum, October is also both a period of rapid stem production and disease progress (36). Therefore, the

Table 7. Coefficients of determination $\left(R^{2}\right)$, intercepts, slopes, standard error of the estimate for $y$ (SEEy), and coefficients of variation $(\mathrm{CV})$ for significant $(F \leq 0.0001)$ linear relationships between reflectance measurements made at different times at Table Cape in 2004

\begin{tabular}{|c|c|c|c|c|c|}
\hline First date, second date, $\mathrm{W}, \mathrm{R}, \mathrm{VI}^{\mathrm{a}}$ & $R^{2 \mathrm{~b}}$ & Intercept & Slope & SEEy & $\mathrm{CV}(\%)$ \\
\hline \multicolumn{6}{|l|}{16 October } \\
\hline $830 \mathrm{~nm}$ & 0.71 & 20.00 & 1.02 & 3.69 & 5.48 \\
\hline $560 / 485$ & 0.31 & 0.59 & 1.16 & 0.66 & 62.77 \\
\hline $830 / 485$ & 0.36 & 3.96 & 2.49 & 5.19 & 51.52 \\
\hline $660 / 560$ & 0.64 & 0.02 & 0.71 & 0.02 & 15.33 \\
\hline $830 / 560$ & 0.59 & 3.23 & 1.15 & 0.44 & 19.77 \\
\hline $1,650 / 560$ & 0.53 & 1.42 & 0.31 & 0.06 & 19.97 \\
\hline $830 / 660$ & 0.63 & 3.36 & 1.94 & 0.89 & 26.96 \\
\hline $1,650 / 830$ & 0.79 & 0.13 & 0.34 & 0.02 & 34.79 \\
\hline NDVI & 0.62 & 0.65 & 0.31 & 0.02 & 22.01 \\
\hline GNDVI & 0.44 & 0.62 & 0.31 & 0.02 & 27.26 \\
\hline DVI & 0.76 & 21.13 & 1.13 & 3.32 & 7.37 \\
\hline RDVI & 0.75 & 3.41 & 0.79 & 0.26 & 13.94 \\
\hline \multicolumn{6}{|l|}{16 October } \\
\hline \multicolumn{6}{|l|}{3 December } \\
\hline $830 \mathrm{~nm}$ & 0.60 & -7.70 & 0.88 & 4.92 & 5.34 \\
\hline $660 / 560$ & 0.49 & 0.76 & 0.39 & 0.01 & 11.49 \\
\hline $1,650 / 560$ & 0.65 & -2.36 & 1.81 & 0.11 & 37.79 \\
\hline $1,650 / 830$ & 0.77 & -0.08 & 2.18 & 0.04 & 43.61 \\
\hline DVI & 0.66 & -4.56 & 0.47 & 2.22 & 8.19 \\
\hline RDVI & 0.59 & -0.69 & 0.46 & 0.19 & 19.92 \\
\hline \multicolumn{6}{|l|}{20 November } \\
\hline \multicolumn{6}{|l|}{3 December } \\
\hline $830 \mathrm{~nm}$ & 0.72 & 0.46 & 1.17 & 4.12 & 4.89 \\
\hline $560 / 485$ & 0.32 & 0.76 & 0.07 & 0.04 & 23.52 \\
\hline $660 / 560$ & 0.55 & 0.68 & 0.37 & 0.01 & 11.17 \\
\hline $1,650 / 560$ & 0.63 & -0.01 & 0.74 & 0.11 & 38.45 \\
\hline $1,650 / 660$ & 0.54 & -0.04 & 0.71 & 0.11 & 39.07 \\
\hline $1,650 / 830$ & 0.87 & 0.15 & 0.89 & 0.03 & 37.86 \\
\hline DVI & 0.77 & 2.19 & 0.65 & 1.84 & 7.49 \\
\hline RDVI & 0.65 & 0.61 & 0.44 & 0.18 & 19.20 \\
\hline
\end{tabular}

${ }^{a}$ Date of first reflectance measurement, date of second reflectance measurement, and wavelengths $(\mathrm{W})$, ratios $(\mathrm{R})$, and vegetative indices $(\mathrm{VI})$. NDVI = normalized difference vegetative index, GNDVI $=$ green normalized difference vegetative index, DVI $=$ difference vegetative index, and RDVI = renormalized difference vegetative index.

${ }^{\mathrm{b}}$ Regression model shown only when $R^{2}$ is greater than 0.3 and $F$ statistics $=0.0001$.

Table 8. Coefficients of determination $\left(R^{2}\right)$, intercepts, slopes, standard error of the estimate for $y$ (SEEy), and coefficients of variation $(\mathrm{CV})$ for significant $(F \leq 0.0001)$ linear relationships between reflectance measurements made on 16 October and 20 November 2004 at Wynyard

\begin{tabular}{lccccc}
\hline $\mathbf{W}, \mathbf{R}, \mathbf{V I}^{\mathbf{a}}$ & $\boldsymbol{R}^{\mathbf{2 b}}$ & Intercept & Slope & SEEy & CV $(\boldsymbol{\%})$ \\
\hline $830 \mathrm{~nm}$ & 0.50 & 18.22 & 0.41 & 2.32 & 3.36 \\
$830 / 560$ & 0.39 & 1.78 & 0.54 & 0.38 & 10.07 \\
$830 / 660$ & 0.36 & 2.10 & 0.44 & 0.60 & 10.20 \\
$1650 / 830$ & 0.67 & -0.02 & 1.11 & 0.01 & 54.10 \\
DVI & 0.51 & 13.70 & 0.42 & 2.30 & 3.93 \\
RDVI & 0.48 & 1.57 & 0.54 & 0.22 & 8.58 \\
\hline
\end{tabular}

${ }^{a}$ Wavelengths $(\mathrm{W})$, ratios $(\mathrm{R})$, and vegetative indices $(\mathrm{VI}) . \mathrm{DVI}=$ difference vegetative index and RDVI = renormalized difference vegetative index

${ }^{\mathrm{b}}$ Regression model shown only when $R^{2}$ is greater than 0.3 and $F$ statistics $=0.0001$. benefits from including reflectance in the green wavelength band in the $830 / 560$ ratio may relate to the rapid production of new leaves and stems at this time. Including reflectance in the green wavelength band also has been beneficial for predicting nitrogen concentrations in rice leaves at specific growth stages (48). However, the consistency of all ratios over time (including 830/560) had high CVs. Guan and Nutter (18) have reported that use of single-wavelength bands in the near infrared had greater precision than reflectancebased ratios. In this study, of all reflectance assessment methods evaluated, only the 830-nm (single) wavelength band and DVI had both acceptable precision and consistency over time across all trials and times (assessment dates), thus also best satisfying requirement (iii), that an assessment method should be applicable over a wide range of conditions. Ratios and indices, derived by combining values of percent reflectance in discrete wavelengths, also have been used to assess their usefulness as indicators of disease severity in the Rhizoctonia-creeping bentgrass pathosystem (42). Our results support their findings, in that a single-wavelength band in the near infrared $(830 \mathrm{~nm})$ was as good as or better than other single-wavelength bands, ratios, and vegetation indices that they evaluated (42).

An additional advantage of the multispectral radiometer are reductions of the inherent variation due to factors such as the effect of wind on reflectance from the canopy (22) and changes in solar intensity and sun angle (16). The variation from sun angle can be further minimized by limiting the acquisition of reflectance measurements within $3 \mathrm{~h}$ of solar noon (17). DVI has been found to further reduce inherent variability due to solar intensity and sun angle $(5,8,24)$. Moreover, this index has been found to have low error when used with dense canopies such as pyrethrum (8). With regards to GLAI, Nutter and Littrell (34) have reported that reflectance in the near-infrared region of 800 to $850 \mathrm{~nm}$ has a linear relationship with GLAI up to GLAI values of 6.0. Although there have been studies that demonstrated vegetative indices, including DVI, to be more reliable than using a single waveband reflectance (5), we believe that the added data conversion of readings in November required to generate vegetative indices did not yield further information in lieu of using a single-wavelength band (e.g., $830 \mathrm{~nm}$ ).

Radiometric assessments of disease intensity were easy to perform (ii) and fast (iv). Measurements of the reflectance of sunlight were easier to perform than visual assessments because it was difficult for assessors to maneuver through a dense canopy of intertwining pyrethrum stems that often were up to $1.2 \mathrm{~m}$ in height. Furthermore, contact with pyrethrum plants can induce skin irritation and hay fever. 
The handheld radiometer sensor, however, could be extended over the pyrethrum canopy at the appropriate angle using a telescopic aluminum pole equipped with a spirit bubble level (17). Thus, this method proved to be noninvasive, nondestructive, and easier to perform compared with visual methods that require entering and damaging the pyrethrum canopy while attempting to follow a systematic sampling design to select and remove stems for visual assessment. Moreover, measurements of reflectance obtained from a handheld radiometer have been shown to be faster and easier to obtain than visual methods of assessment in several other pathosystems $(18,24,32,34,35)$. In our study, we found radiometric assessment of plots to be approximately three times faster than visual disease assessments, without the need to physically remove stems for visual assessments.

As noted by Steddom et al. (45) and, earlier, by Nutter et al. (32), radiometric data has the additional advantage of being free of rater bias when compared with visual disease assessments. This is especially important in trials where the goal is to determine how candidate fungicides or fungicide programs rank in terms of disease control (i.e., achieving the level of crop health necessary to cost-effectively achieve attainable yields; 30). The precision and reproducibility of an assessment system are of critical importance to provide the statistical resolution necessary to differentiate and rank treatments, or to make decisions on fungicide applications to commercial crops when disease intensity reaches thresholds that will impact negatively on yield. Determining the coefficient of variations for each assessment method provided an index to compare assessment methods for their resolution in discriminating among disease levels and their impact on crop health. Coefficients of variation were lowest for percent reflectance for the ratio 830/560 in October and the 830-nm and DVI in November; therefore, these two methods should best be able to assess disease intensity.

We recommend that percentage of reflectance be used as an assessment method when noninvasive and nondestructive assessments are desired and that this method can be used in lieu of (or in addition to) visual assessment methods that are difficult to perform and result in crop damage in the pyrethrum-ray blight pathosystem.

\section{ACKNOWLEDGMENTS}

This project was funded by Botanical Resources Australia Pty. Ltd., Horticulture Australia Limited, and the Australian Research Council (programs LP0211065 and LP0560562). P. Esker also was supported through the National Science Foundation under Grant No. 0091953. We thank the pyrethrum growers who allowed access to their crops for field trials and T. Groom, Botanical Resources Australia Pty. Ltd., for constructive discussion.
LITERATURE CITED

1. Anonymous 1956. Ray blight of chrysanthemums. Agric. Gaz. 309-310.

2. Baker, K. F., and Davis, L. H. 1959. Ascochyta disease of chrysanthemum appears in California. Calif. State Florists Assoc. Mag. 8:A-B.

3. Baker, K. F., Dimock, A. W., and Davis, L. H. 1949. Life history and control of the Ascochyta ray blight of chrysanthemum. Phytopathology 39:789-805.

4. Baker, K. F., Dimock, A. W., and Davis, L. H. 1961. Cause and prevention of the rapid spread of the Ascochyta disease of chrysanthemum. Phytopathology 51:96-101.

5. Baret, F., and Guyot, G. 1991. Potentials and limits of vegetation indices for LAI and APAR assessment. Remote Sens. Environ. 35:161-173.

6. Bausch, W. C., and Duke, H. R. 1996. Remote sensing of plant nitrogen status in corn. Trans. Am. Soc. Agric. Eng. 39:1869-1875.

7. Blazquez, C. H., and Edwards, G. J. 1986. Spectral reflectance of healthy and diseased watermelon leaves. Ann. Appl. Biol. 108:243249.

8. Broge, N. H., and Leblanc, E. 2000. Comparing prediction power and stability of broadband and hyperspectral vegetation indices for estimation of green leaf area index and canopy chlorophyll density. Remote Sens. Environ. 76:156-172.

9. Calpouszos, L., Roelfs, A. P., Madson, M. E., Martin, F. B., Welsh, J. R., and Wilcoxson, R. D. 1976. A new model to measure yield losses caused by stem rust in spring wheat. Minn. Agric. Exp. Stn. Tech. Bull. 307.

10. Campbell, C. L., and Madden, L. V. 1990. Page 1111 in: Introduction to Plant Disease Epidemiology. John Wiley \& Sons, New York.

11. Casida, J. E., and Quistad, G. B. 1995. Pyrethrum Flowers: Production, Chemistry, Toxicology and Uses. Oxford University Press, New York.

12. Fox, R. T. V. 1998. Chrysanthemum ray blight. Mycologist 12:135-136.

13. Gamon, J. A., and Surfus, J. S. 1999. Assessing leaf pigment content and activity with a reflectometer. New Phytol. 143:105-117.

14. Gaunt, R. E. 1980. Physiological basis of yield loss. Pages 98-111 in: Crop Loss Assessment, Proc. E. C. Stakman Commemorative Symp. P. S. Teng and S. V. Krupa, eds. Univ. Minn. Agric. Exp. Stn. Misc. Publ. 7.

15. Gitelson, A. A., and Merzlyak, M. N. 1997. Remote estimation of chlorophyll content in higher plant leaves. Int. J. Remote Sens. 18:2691-2697.

16. Gross, M. F., Hardisky, M. A., and Klemas, V. 1988. Effects of solar angle on reflectance from wetland vegetation. Remote Sens. Environ. 26:195-212.

17. Guan, J., and Nutter, F. W., Jr. 2001. Factors affecting the quality and quantity of sunlight reflected from alfalfa canopies. Plant Dis. 85:865-874.

18. Guan, J., and Nutter, F. W., Jr. 2004. Comparison of single-point alfalfa yield models based on visual disease intensity and remote sensing assessments. Can. J. Plant Pathol. 26:314-324.

19. Johnson, K. B. 1987. Defoliation, disease and growth: a reply. Phytopathology 77:14951497.

20. Kobayashi, T., Kanda, E., Kitada, K., Ishiguro, K., and Torigoe, Y. 2001. Detection of rice panicle blast with multispectral radiometer and the potential for using airborne multispectral scanners. Phytopathology 91:316-323.

21. Lathrop, L. D., and Pennypacker, S. 1980. Spectral classification of tomato disease severity levels. Photogram. Eng. Remote Sens. 143:439-445.

22. Lord, D., DesJardins, R. L., and Dube, P. A. 1985. Influence of wind on crop canopy reflectance measurements. Remote Sens. Environ. 18:113-123.
23. Moreira, A. J. 2004. Detecting and quantifying soybean cyst nematode infestations using remote sensing and geographic information systems. Ph.D. Diss. Iowa State University, Ames.

24. Newton, A. C., Hackett, C. A., Lowe, R., and Wale, S. J. 2004. Relationship between canopy reflectance and yield loss due to disease in barley. Ann. Appl. Biol. 145:96-106.

25. Nilsson, H. E. 1995. Remote sensing and image analysis in plant pathology. Annu. Rev. Phytopathol. 15:489-527.

26. Nilsson, M., Elmqvist, T., and Carlsson, U. 1994. Use of near-infrared reflectance spectrometry and multivariate data analysis to detect anther smut disease (Microbotrytum violaceum) in Silene dioica. Phytopathology 84:764-770.

27. Nilsson, H. E., and Johnsson, L. 1996. Handheld radiometry of barley infected by barley stripe in a field experiment. J. Plant Dis. Prot. 103:517-526.

28. Nutter, F. W., Jr. 1989. Detection and measurement of plant disease gradients in peanut with a multispectral radiometer. Phytopathology 79:958-963.

29. Nutter, F. W., Jr. 1990. Remote sensing and image analysis for crop loss assessment. Pages 93-105 in: Crop Loss Assessment in Rice. International Rice Research Institute, Los Banos, Philippines

30. Nutter, F. W., Jr. 2001. Disease assessment terms and concepts. Pages 313-323 in: Encyclopedia of Plant Pathology. O. C. Maloy and T. D. Murray, eds. John Wiley \& Sons Inc. New York.

31. Nutter, F. W., Jr., and Gaunt, R. E. 1996. Recent developments in methods for assessing disease losses in forage/pasture crops. Pages 93-118 in: Pasture and Forage Crop Pathology. S. Chakraborty, K. T. Leath, R. A. Skipp, G. A Pederson, R. A. Bray, G. C. M. Latch, and F W. Nutter, Jr., eds. American Society of Agronomy, Crop Science Society of America, and Soil Science Society of America, Madison, WI.

32. Nutter, F. W., Jr., Gleason, M. L., Jenco, J. H., and Christians, N. C. 1993. Assessing the accuracy, intra-rater repeatability, and inter-rater reliability of disease assessment systems. Phytopathology 83:806-812.

33. Nutter, F. W., Jr., Guan, J., Gotlieb, A. R., Rhodes, L. H., Grau, C. R., and Sulc, R. M 2002. Quantifying alfalfa yield losses caused by foliar diseases in Iowa, Ohio, Wisconsin, and Vermont. Plant Dis. 86:269-277.

34. Nutter, F. W., Jr., and Littrell, R. H. 1996. Relationships between defoliation, canopy reflectance and pod yield in the peanut-late leafspot pathosystems. Crop Prot. 15:135-142.

35. Nutter, F. W., Jr., Littrell, R. H., and Brenneman, T. B. 1990. Utilization of a multispectral radiometer to evaluate fungicide efficacy to control late leaf spot in peanut. Phytopathology 80:102-108.

36. Pethybridge, S. J., Esker, P. D., Hay, F. S., Wilson, C. R., and Nutter, F. W. Jr. 2005. Spatiotemporal description of epidemics caused by Phoma ligulicola in Tasmanian pyrethrum fields. Phytopathology 95:648-658.

37. Pethybridge, S. J., and Hay, F. S. 2001. Influence of Phoma ligulicola on yield and site factors on disease development in Tasmanian pyrethrum crops. Aust. Plant Pathol. 30:17-20.

38. Pethybridge, S. J., Hay, F. S., and Groom, T. 2003. Seasonal fluctuations in fungi associated with pyrethrum foliage in Tasmania. Aust. Plant Pathol. 32:223-230.

39. Pethybridge, S. J., Hay, F. S., and Wilson, C. R. 2004. Pathogenicity of fungi commonly from Tasmanian pyrethrum crops. Aust. Plant Pathol. 33:441-444.

40. Pethybridge, S. J., Hay, F. S., Wilson, C. R., and Groom, T. 2005. Development of a fungicide-based management strategy for foliar dis- 
ease caused by Phoma ligulicola in Tasmanian pyrethrum fields. Plant Dis. 89:1114-1120.

41. Pethybridge, S. J., and Wilson, C. R. 1998. Confirmation of ray blight disease of pyrethrum in Australia. Aust. Plant Pathol. 27:4548.

42. Raikes, C., and Burpee, L. L. 1998. Use of multispectral radiometry for assessment of Rhizoctonia blight in creeping bentgrass. Phytopathology 88:446-449.

43. Safir, G. R., Svits, G. H., and Ellingboe, A. H.
1972. Spectral reflectance and transmittance of corn leaves infected with Helminthosporium maydis. Phytopathology 62:1210-1213.

44. Shokes, F. M., Berger, R. D., Smith, D. H., and Rasp, J. M. 1987. Reliability of disease assessment procedures: A case study with late leafspot of peanut. Oleagineux 42:245-251.

45. Steddom, K., Bredehoeft, M. W., Khan, M., and Rush, C. M. 2005. Comparison of visual and multispectral radiometric disease evaluations of Cercospora leaf spot of sugar beet.
Plant Dis. 89:153-158.

46. Strider, D. L. 1994. Chrysanthemum diseases: a grower's guide. Rev. Chapingo Ser. Hortic. 1:131-135.

47. Waggoner, P. E., and Berger, R. D. 1987. Defoliation, disease, and growth. Phytopathology 77:393-398.

48. Xue, L., Cao, W., Luo, W., Dai, T., and Zhu, Y. 2004. Monitoring leaf nitrogen status in rice with canopy spectral reflectance. Agron. J. 96:135-142. 